\title{
SISTEM INFORMASI INVENTORY BARANG (SI RIANG) PADA PT SANGHIANG PERKASA
}

\author{
Eka Chandra Ramdhani ${ }^{1}$, Juniarti Eka Safitri ${ }^{2}$, Selamat Abdurrahman Fahmi ${ }^{3}$, Asep ${ }^{4}$ \\ 1,3,4 Universitas BSI \\ ${ }^{2}$ STMIK Nusa Mandiri \\ Email: eka.ecr@bsi.ac.id, junesafitri@gmail.com, slamat_af@gmail.com, asep.aep@bsi.ac.id
}

\begin{abstract}
The inventory system is a system that has a very important role in a company. Inventory systems have been widely used or developed in a place with various technologies and systems. Problems at PT. Sanghiang Perkasa is due to the fact that the data has not been stored in a good file and the management and processing of inventory data is still processed in a conventional way, which has a very significant effect on the quality of the data and information produced. The main objective of this research is to produce an inventory system that is powerful and in accordance with the needs of the users associated with the inventory system. The system development method in this inventory system uses the waterfall method which consists of six stages. The stages are System Analysis and Design, software requirements analysis, system design, coding, system testing and maintenance. This system was built using the PHP programming language, DataBase MySQL. It is hoped that with the implementation of this inventory system at PT. Sanghiang Perkasa can make it easier to store and process data and information such as stock-taking data, information on incoming and outgoing goods transactions, purchase and sales return data, managing customer and supplier data to making product stock reports and assembly reports.
\end{abstract}

Keywords: Information System; Inventory, Web

\begin{abstract}
Abstrak
Sistem inventori merupakan suatu sistem yang sangat penting peranananya didalam sebuah perusahaan. Sistem inventori sudah banyak digunakan atau dikembangkan pada suatu tempat dengan berbagai macam teknologi dan sistem. Permasalahan pada PT Sanghiang Perkasa ini disebabkan data belum tersimpan dalam file yang baik serta pengelolaan dan pengolahan data persediaan barang masih diproses dengan cara yang konvensional sehingga mengakibatkan efek yang sangat signifikan terhadap kualitas data dan informasi yang dihasilkan. Tujuan utama dari Penelitian ini adalah untuk menghasilkan Sistem inventori yang powerfull dan sesuai dengan kebutuhan user yang terkait didalam sistem inventori tersebut. Metode pengembangan sistem pada sistem inventori ini menggunakan metode waterfall yang terdiri dari enam tahapan. Adapun tahapan tersebut yaitu Analisis dan Perancangan Sistem, analisis kebutuhan perangkat lunak, perancangan sistem, pengkodean, pengujian dan pemeliharaan sistem. Sistem ini dibangun dengan menggunakan bahasa pemrograman PHP, DataBase MySQL. Diharapkan dengan diterapkannya sistem inventori ini di PT Sanghiang Perkasa dapat mempermudah peyimpanan serta pemrosesan data dan informasi seperti data stock opname, informasi transaksi barang masuk dan barang keluar, data retur pembelian dan penjualan, mengelola data customer dan supplier hingga pembuatan laporan stok produk dan laporan assembly.
\end{abstract}

Keywords: Sistem Informasi, Inventori, Web

\section{Article History:}

Jurnal Interkom: Jurnal Publikasi Ilmiah Bidang Teknologi Informasi dan Komunikasi

Volume 15 Nomor 04 Bulan Januari - Tahun 2021 
Accepted 4, Januari, 2021

\section{Corresponding Author:}

Nama Penulis, Ayu Datari Mareta

Departemen, Universitas BSI

Instansi, Universitas BSI

Alamat. Jl.Taman Kota Rt.016/005 No.72 Kel.Kembangan Utara Kec.Kemban gan Jakarta Barat 11610.

Email Penulis.eka.ecr@bsi.ac.id

\section{PENDAHULUAN}

PT Sanghiang Perkasa yang merupakan anak perusahaan PT Kalbe Farma Tbk yang bergerak dalam industri minuman dan makanan kesehatan dan kini menyandang nama Kalbe Nutritionals. PT Sanghiang Perkasa memiliki begitu banyak barang-barang bahan baku yang perlu di kelola agar dapat tersedia dengan baik, hal tersebut dapat terwujud ketika adanya sistem informasi yang tepat guna.

Sistem informasi merupakan hal yang penting dalam suatu organisasi atau perusahaan. Dengan adanya sistem informasi, organisasi atau perusahaan dapat menjamin kualitas informasi yang disajikan dan dapat mengambil keputusan berdasarkan informasi tersebut. Sekarang informasi dapat diperoleh dengan lebih mudah dan cepat, berkat adanya teknologi informasi. Salah satu pemanfaatan teknologi informasi yang diharapkan adalah pada sistem inventori barang.[1]

Adapun jumlah penerimaan barang bahan baku ini perhari itu mencapai kurang lebih 150 Ton dengan berbagai item kedatangan setiap harinya, sedangkan jumlah item yang ada di perusahaan PT Sanghiang Perkasa, khusus untuk bahan bakunya sendiri kurang lebih 106 item barang, dan memiliki kurang lebih 32 supplier, dari data tersebut maka di perlukan sistem inventory yang efektif dan efisien.
Di dalam bagian inventory sangat di perlukan ke akuratan, ketepatan dan keseimbangan antara pengeluaran dan pemasukan, serta mampu mengelola barang masuk dan barang keluar dengan baik. Bagian ini sering di sebut dengan bagian gudang (warehouse), ternyata kriteria tersebut belum dapat terpenuhi pada warehouse yang ada di PT Sanghiang Perkasa.

Kendala yang di alami sering terjadi ketimpangan dan ketidak seimbangan, antara pemasukan dan pengeluarannya, bahkan seringkali dalam bagian penyiapan terjadi kendala dengan barang yang tidak sesuai item code atau barang yang akan di kirim kepada konsumen, dengan keadaan tersebut waktu yang di butuhkan akan semakin lama untuk menyiapkan barang yang di butuhkan. Selain itu untuk mengetahui laporan Stok barang dan Transaksi Pembelian serta Penjualan membutuhkan waktu yang cukup lama. Hal ini terjadi di karenakan belum adanya sistem yang terkomputerisasi untuk menangani hal tersebut karena informasi yang biasanya didapatkan dengan cara yang tradisional atau manual, sudah tidak dapat digunakan lagi secara maksimal dalam memenuhi kebutuhan perusahaan karena perusahaan menginginkan adanya informasi yang akurat dan cepat.[2]

Dengan melihat permasalahan yang terdapat pada PT Sanghiang Perkasa, solusi yang ditawarkan adalah pengunan web 
intranet antar entitas yang berada pada perusahaan tersebut supaya kegiatan pencatatan, penerimaan dan pengeluaran barang, menjadi lebih cepat, ringkas kemudian untuk menjaga keakuratan data serta untuk menghasilkan laporan yang tepat waktu.

\section{Tinjauan Pustaka \\ a. Sistem Informasi}

Sistem informasi dapat didefinisikan secara teknis sebagai satuan komponen yang saling berhubungan yang mengumpulkan (atau mendapatkan kembali), memproses, menyimpan, dan mendistribusikan informasi untuk mendukung pengambilan keputusan dan kendali dalam suatu organisasi. [3]

Sistem informasi adalah suatu bentuk sarana pendukung untuk merekap data serta dapat menampilkan suatu bentuk laporan dari rekapan data tersebut lengkap dengan tanggal serta waktu pada saat penginputan data tersebut[4].

\section{b. Konsep Dasar Web}

Web adalah sebuah sistem dengan informasi yang disajikan dalam bentuk teks, gambar, suara, dan lain-lain yang tersimpan dalam sebuah server web internet yang disajikan dalam bentuk hiperteks. Informasi web dalam bentuk teks umumnya adalah HTML (Hypertext Markup Language). Informasi lainnya yang disajikan dalam bentuk grafis (dalam format GIF, JPG, PNG, dll), suara (dalam format AU, WAV, dll), dan objek multimedia lainnya (seperti MIDI, Shockwave, Quicktime, Movie, 3D World).

Pada dasarnya web merupakan suatu kumpulan hyperlink yang menuju dari alamat satu ke alamat lainnya dengan bahasa HTML (Hyper Text Markup Language). Seiring perkembangannya web tidak lagi berbentuk statis yang hanya menampilkan informasi teks dan gambar saja, tetapi sudah menjadi dinamis dimana informasi yang ditampilkan bisa diperbaharui secara berkala tanpa harus membuat halaman baru berkat adanya dukungan dari basis data, juga bahasa pemrograman berbasis web yang semakin berkembang seperti: ASP, PHP, JSP, dan lain sebagainya. [5]

\section{c. Website}

Website adalah keseluruhan halaman-halaman web yang terdapat dalam sebuah domain yang mengandung informasi. Sebuah website biasanya dibangun atas banyak halaman web yang saling berhubungan. Hubungan antara satu halaman web dengan halaman web yang lainnya disebut dengan hyperlink, sedangkan teks yang dijadikan media penghubung disebut hypertext.[6]

\section{d. Internet}

Internet adalah rangkaian hubungan jaringan komputer yang dapat diakses secara umum diseluruh dunia, yang mengirimkan data dalam bentuk paket data berdasarkan standar Internet Protocol (IP)" Lebih dalam lagi, internet adalah kumpulan jaringan dari jaringan-jaringan komputer dunia yang terdiri dari jutaan unit-unit kecil, seperti jaringan pendidikan, jaringan bisnis, jaringan pemerintahan dan lain-lain, yang secara bersama menyediakan layanan informasi seperti e-mail, online chat, transfer file dan saling keterhubungan (linked) antara satu halaman web dengan sumber halaman web yang lainnya.

Dari definisi di atas, dapat disimpulkan bahwa layanan utama internet sebagai media untuk:

1) Menyebarkan dan memperoleh informasi, umumnya disajikan dalam bentuk website, informasi dapat berupa 
teks, grafik, suara, video atau dalam bentuk file yang dapat di-download.

2) Berkomunikasi, baik melalui media chatting berbasis teks (IRC), grafik (Yahoo Massenger), maupun berkomunikasi suara (Skype), layaknya menggunakan telpon kabel.

3) Berkirim surat (E-mail).

4) Bertukar data, salah satunya dengan menggunakan aplikasi FTP, website, maupun koneksi peer to peer.

5) Remote login, mampu mengeksekusi komputer dari jauh (telnet).[6]

\section{e. World Wide Web}

World Wide Web atau Web merupakan sistem informasi terdistribusi yang berbasis hypertext. Dokumendokumen yang dikelola dalam Web bisa beraneka jenis (pengolah kata, lembar kerja, tabel, basis data, presentasi, hypertext dan lain-lain) dan beragam format (.doc, .pdf, .xls, .dbf, .ppt, .htm dan lain-lain) Jenis dokumen yang paling umum adalah dokumen Hypertext yang dibentuk berdasarkan format HTML (HyperText Markup Language). [7]

\section{f. Aplikasi Berbasis Web}

Aplikasi berbasis web adalah sebuah sistem informasi yang mendukung interaksi pengguna melalui antar muka berbasis web. Aplikasi berbasis web tidak perlu di instal dimasing-masing client pengakses aplikasi, karena aplikasi cukup dikonfirmasi di server. Kemudian client mengakses dari browser seperti Google Crome, Mozila Firefox, Internet Explorer. Excutor aplikasi dilakukan oleh web server seperti Apache, Xатрp dan lain sebagainya.

Interaksi web dibagi ke dalam tiga langkah, yaitu:

1) Permintaan

Pengguna mengirimkan permintaan ke server web, biasanya via halaman web yang ditampilkan pada browser web.

\section{2) Pemprosesan}

Server web menerima permintaan yang dikirim oleh pengguna, kemudian permintaan tersebut di proses.

3) Jawaban

Browser menampilkan hasil dari permintaan pada jendela browser.

Halaman web bisa terdiri dari permintaan jenis informasi grafis (tekstual dan multimedia). Kebanyakan komponen grafis dihasilkan dengan tool khusus, menggunakan manipulasi langsung dan editor WYSIWYG (What You See Is What You Get).[5]

\section{f. Basis Data}

Basis Data terdiri atas 2 kata, yaitu Basis dan Data. Basis kurang lebih dapat diartikan sebagai markas atau gudang, tempat bersarang atau berkumpul. Sedangkan Data adalah refresentasi fakta dunia nyata yang mewakili suatu objek seperti manusia (pegawai, siswa, pembeli, pelanggan), barang, hewan, peristiwa, konsep, keadaan, dan sebagainya, yang berwujudkan dalam bentuk angka, huruf, simbol, teks, gambar, bunyi, atau kombinasinya.

Sebagai satu kesatuan istilah, Basis Data (Database) sendiri dapat didefinisikan dalam sejumlah sudut pandang seperti:

1) Himpunan kelompok data ( arsip ) yang saling berhubungan yang diorganisasi sedemikian rupa agar kelak dapat dimanfaatkan kembali dengan cepat dan mudah.

2) Kumpulan data yang saling berhubungan yang disimpan secara bersama sedemikian rupa dan tanpa pengulangan (redudansi) yang tidak perlu untuk memenuhi berbagai kebutuhan.

3) Kumpulan file atau tabel atau arsip yang saling berhubungan yang disimpan dalam media penyimpanan elektronis. [7] 


\section{g. MySQL}

MySQL adalah sebuah perangkat lunak sistem manajemen basis data SQL (database management system) atau DBMS yang multithread, multi-user, dengan sekitar 6 juta instalasi di seluruh dunia. MySQL AB membuat MySQL tersedia sebagai perangkat lunak gratis dibawah lisensi GNU General Public License (GPL), tetapi mereka juga menjual dibawah lisensi komersial untuk kasuskasus dimana penggunaannya tidak cocok dengan penggunaan GPL.

MySQL sebenarnya merupakan turunan salah satu konsep utama dalam database sejak lama, yaitu SQL (Structured Query Language). SQL adalah sebuah konsep pengoperasian database, terutama untuk pemilihan atau seleksi dan pemasukan data, yang memungkinkan pengoperasian data dikerjakan dengan mudah secara otomastis.[8]

\section{h. Inventory}

Inventory atau sering disebut persediaan merupakan simpanan barangbarang mentah, material atau barang jadi yang disimpan untuk digunakan dalam masa mendatang atau dalam kurun waktu tertentu. Persediaan barang sangat penting dalam suatu perusahaan dalam menghadapi perubahan pasar produksi serta mengantisipasi perubahan harga dalam permintaan barang yang banyak. Pengertian persediaan/ inventory yaitu sebagai berikut. Inventory adalah sejumlah sumber daya baik berbentuk bahan mentah ataupun barang jadi yang disediakan perusahaan untuk memenuhi permintaan dari konsumen. Sedangkan pengertian inventory dalam definisi lainnya adalah suatu teknik untuk manajemen material yang berkaitan dengan persediaan.[9]

Inventory dalam bahasa indonesia di sebut "persediaan" adalah seluruh bentuk barang - barang, baik barang mentah, barang yang sedang dalam proses produksi maupun barang jadi yang di miliki oleh perusahaan dengan maksud untuk di jual dan agar dapat memenuhi permintaan konsumen yang di simpan serta di rawat menurut aturan tertentu dalam suatu tempat agar selalu dalam keadaan siap pakai jika sewaktu waktu barang tersebut di perlukan, istilah persediaan sering kali digunakan untuk menggambarkan stok barang yang dimiliki oleh perusahaan.

Persediaan biasanya dikelola sedemikian rupa sehingga perusahaan berada pada zona aman dari berbagai kemungkinan yang bisa mengancam perusahaan terkait dengan suplay bahan baku ataupun produk jadi yang mereka butuhkan.

Inventory sangat dibutuhkan oleh perusahaan untuk menjamin kelancaran aktivitas usahanya. Seperti yang kita ketahui bersama, tidak ada yang pasti dalam aktivitas usaha. Berbagai macam kemungkinan bisa saja mengancam keberlangsungan usaha seperti keterlambatan pasokan bahan baku ataupun kerusakan mesin produksi yang mengakibatkan perusahaan tidak mampu menghasilkan produk. Ketika perusahaan memiliki persediaan, baik itu bahan baku ataupun barang jadi, maka perusahaan dapat terus menjalankan aktivitas usahanya meskipun berbagai macam kemungkinan di atas terjadi.

Selain itu, dengan membuat Inventory, manajemen perusahaan juga bisa lebih bebas dalam mengatur jadwal produksi ataupun operasi perusahaan. Perusahaan tidak perlu bergantung dengan perusahaan lainnya yang bertindak sebagai penyuplai bahan baku, sehingga tingkat barganing position perusahaan pun dapat lebih ditingkatkan. 
Inventory memiliki banyak sekali manfaat bagi dunia usaha. Beberapa manfaat Inventory dalam dunia usaha yaitu:

1. Sebagai antisipasi kemungkinan terjadinya keterlambatan kedatangan barang ataupun barang-barang yang dibutuhkan perusahaan dalam aktivitas usahanya.

2. Sebagai antisipasi kemungkinan terjadinya cacat pada barang yang dipesan sehingga harus diretur kembali ke perusahaan asal.

3. Sebagai antisipasi terjadinya kelangkaan barang-barang tertentu yang tidak dapat diproduksi sepanjang musim.

4. Untuk mempertahankan dan menjaga aktivitas operasional perusahaan sekaligus menjamin keberlangsungan aktivitas produksi dalam perusahaan.

5. Untuk mengoptimalkan penggunaan mesin yang dimiliki oleh perusahaan.

6. Untuk memberikan tingkat kepuasan optimal untuk setiap pelanggan melalui ketersediaan barang ataupun jasa yang tepat waktu dan juga tepat guna untuk setiap pelanggan.

7. Untuk mengantisipasi kemungkinan terjadinya produksi yang tidak sesuai dengan yang dibutuhkan oleh perusahaan. [10]

\section{METODE}

\section{a. Pengembangan Perangkat Lunak}

Model SDLC air terjun (waterfall) sering juga disebut model sekuensial linier (sequential linear) atau alur hidup klasik (classic life cycle). Berikut adalah gambar model air terjun (waterfall).

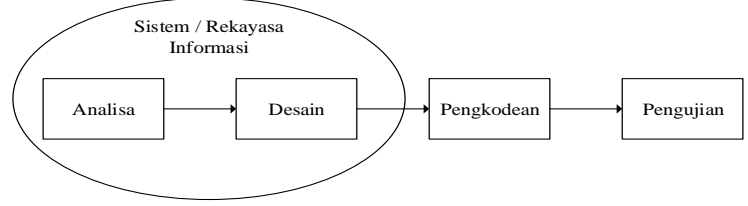

Gambar 1. Model Waterfall
1) Analisa kebutuhan perangkat lunak

Proses pengumpulan kebutuhan dilakukan secara intensif untuk menspesifikasikan kebutuhan perangkat lunak agar dapat dipahami perangkat lunak seperti apa yang dibutuhkan oleh user. Dimulai dari analisa kebutuhan sistem dianalisan kelemahan sistem yang lama dibandingkan dengan sistem yang diajukan kemudian analisa kebutuhan pengguna diidentifikasi actor atau entitas yang berperan dalam sistem seperti adanya admin, user, dan supervisior.

2) Desain

Desain perangkat lunak adalah proses multi langkah yang fokus pada desain pembuatan program perangkat lunak termasuk struktur data, arsitektur prangkat lunak, representasi antarmuka, dan prosedur pengkodean. Tahap ini mentanslasi kebutuhan perangkat lunak dari tahap analisis kebutuhan ke representasi desain agar dapat diimplementasikan menjadi program pada tahap selanjutnya. Didalam desain ini, melakukan perancangan database terlebih dahulu menggunakan tools ERD dan LRS selanjutnya untuk membuat gambaran alur dari web yang dibuat menggunakan tools struktur navigasi.

3) Pembuatan kode program

Desain harus ditranslasikan ke dalam program perangkat lunak. Hasil dari tahap ini adalah program komputer sesuai dengan desain yang telah dibuat pada tahap desain. Bahasa script PHP dipilih dalam digunakan dalam pembuatan web intranet ini. PHP adalah bahasa pemrograman berbentuk skrip yang mengandung fungsi-fungsi dalam membentuk sistem yang sistematis.[11]

4) Pengujian

Pengujian fokus pada perangkat lunak secara dari segi lojik dan fungsional dan

Jurnal Interkom: Jurnal Publikasi Ilmiah Bidang Teknologi Informasi dan Komunikasi

Volume 15 Nomor 04 Bulan Januari - Tahun 2021 
memastikan bahwa semua bagian sudah diuji. Hal ini dilakukan untuk meminimalisir kesalahan (error) dan memastikan keluaran yang dihasilkan sesuai dengan yang diinginkan.

5) Pendukung (Support) atau Pemeliharaan (Maintenance)

Tidak menutup kemungkinan sebuah perangkat lunak mengalami perubahan ketika sudah dikirimkan ke user. Perubahan bisa terjadi karena adanya kesalahan yang mucul dan tidak terdeteksi saat pengujian atau perangkat lunak harus beradaptasi dengan lingkungan yang baru. Tahap pendukung atau pemeliharaan dapat mengulangi proses pengembangan mulai dari analisis spesifikasi untuk perubahaan perangkat lunak yang sudah ada, tapi tidak untuk membuat perangkat lunak baru.

Model air terjun (watefall) sangat cocok digunakan kebutuhan pelanggan sangat di pahami dan kemungkinan terjadinya perubahan kebutuhan selama pengembangan perangkat lunak kecil, hal positif dari model air terjun adalah struktur tahap pengembangan sistem jelas, dokumentasi dihasilkan disetiap tahap pengembangan, dan sebuah tahap dijalankan setelah tahap sebelumnya selesai dijalankan (tidak ada tumpang tindih pelaksanaan tahap). [12]

\section{b. Metode Pengumpulan Data}

Teknik pengumpulan data yang digunakan oleh penulis dalam melakukan pengumpulan data adalah :

1) Metode Observasi (Observation)

Observasi merupakan teknik

pengumpulan data dengan cara

mengadakan pengamatan langsung dilapangan terhadap objek yang akan diteliti untuk mendapatkan informasi yang akan dipergunakan untuk penelitian ini. Dalam hal ini bagian inventory yang akan di observasi

2) Metode Wawancara (Interview)

Wawancara ini kami lakukan langsung di PT. SANGHIANG PERKASA. Dalam wawancara ini kami langsung mewawancarai Bpk. Heri Iwan Susanto selaku Kepala Unit Inventory ( $\mathrm{KU}$ ) yang biasa menangani persediaan barang gudang.

3) Metode Studi Pustaka (Library Research)

Mengumpulkan dari sumber-sumber tertulis seperti buku dan jurnal yang terkait.

\section{Hasil dan pembahasan}

\section{a. Analisa Kebutuhan Sistem}

Langkah pertama yang dilakukan dalam menganalisa sebuah sistem adalah mengidentifikasi masalah yang ada dalam sistem tersebut. Subjek permasalahan yang terjadi pada Stok Barang adalah masih menggunakan sistem manual. Secara garis besar, analisa kebutuhan sistem disajikan dalam tabel dibawah ini.

Tabel 1. Analisa Kebutuhan Sistem 


\begin{tabular}{|c|c|c|}
\hline ANALISA & KELEMAHAN SISTEM LAMA & SISTEM YANG DIAJUKAN \\
\hline Information & $\begin{array}{l}\text { Informasi tentang Stok Baxang terbanu } \\
\text { didapatijikakeppala gudang menanyakan } \\
\text { ke staff langsung ke lokasi gudang } \\
\text { penyimpananbarangyangmembutulukan } \\
\text { wakktu lama. }\end{array}$ & 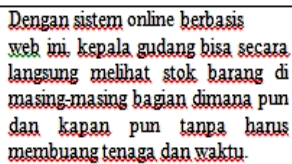 \\
\hline Performance & $\begin{array}{l}\text { Staff gudang masih secara langsung ke } \\
\text { tempat penximpanan barang untuk } \\
\text { mengetahui stok terban. }\end{array}$ & $\begin{array}{l}\text { Dengan sistem berbasis web atau } \\
\text { online, user atau staff gudang dapat } \\
\text { melihat stok barang terbanu melalui } \\
\text { website. }\end{array}$ \\
\hline Eficiencx & $\begin{array}{l}\text { Waktu yang banyak terbuang karena } \\
\text { staff gudang hanus datang langsung } \\
\text { untuk melihat stok terbanu. }\end{array}$ & $\begin{array}{l}\text { User atau staff dapat menghemat } \\
\text { yakttu dengan menggunakan } \\
\text { fasilitas website infemasi akan } \\
\text { dilakukan otomatis eleh komputer } \\
\text { sehingga infomasi lebil cepat dan } \\
\text { efisien. }\end{array}$ \\
\hline $\begin{array}{l}\text { Control/ } \\
\text { Security }\end{array}$ & $\begin{array}{l}\text { Data transakssi barang keluar masuk } \\
\text { tersimpan dalam dokumen kertas dan } \\
\text { sangat niskan apabila dokumen rusak } \\
\text { ataubahahkan bilang }\end{array}$ & 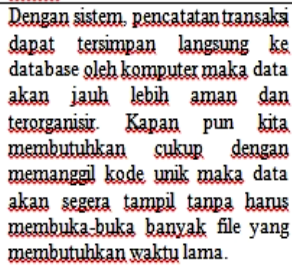 \\
\hline Economy & $\begin{array}{l}\text { Pencatatan transaksi secara manual, baik } \\
\text { surat ialan maupun laporan memakan } \\
\text { biaya untulk pengadaan kertas dan tinta. }\end{array}$ & $\begin{array}{l}\text { Pencatatan transaksi yang langsung } \\
\text { tersimpan ke database dan dapat } \\
\text { dilihat di website yang diharapkan } \\
\text { meingankan biaya. }\end{array}$ \\
\hline
\end{tabular}

\section{b. Analisa Kebutuhan Pengguna}

Berdasarkan hasil analisis dari permasalahan yang ada dalam perusahaan, diperoleh kebutuhan pengguna sebagai berikut:

\section{1) Halaman Admin:}

- Mengelola data pengguna / staff

- Mengelola data barang

- Mengelola data supplier

- Mengelola customer

- Melakukan transaksi barang masuk

- Melakukan transaksi barang keluar

- Melihat dan mencetak laporan.

- Melihat Stock Opname

- Mengelola Retur Pembelian dan

Penjualan

○ Melihat dan mencetak laporan

\section{2) Halaman User:}

- Mengelola data barang

- Mengelola data supplier

- Mengelola customer

- Melihat dan mencetak laporan.

\section{3) Halaman Spv:}

○ Melihat Barang Bukti Masuk

- Melihat Laporan Stok Produk

- Melihat Laporan Assembly

- Melihat dan mencetak laporan

4) Halaman Top:

Melihat Keseluruhan hasil Laporan

\section{c. Rancangan Basis Data}

Perancangan basis data menghasilkan pemetaan tabel-tabel yang digambarkan dengan Entity Relationship Diagram (ERD), Logical Record Structure (LRS), Spesifikasi File.

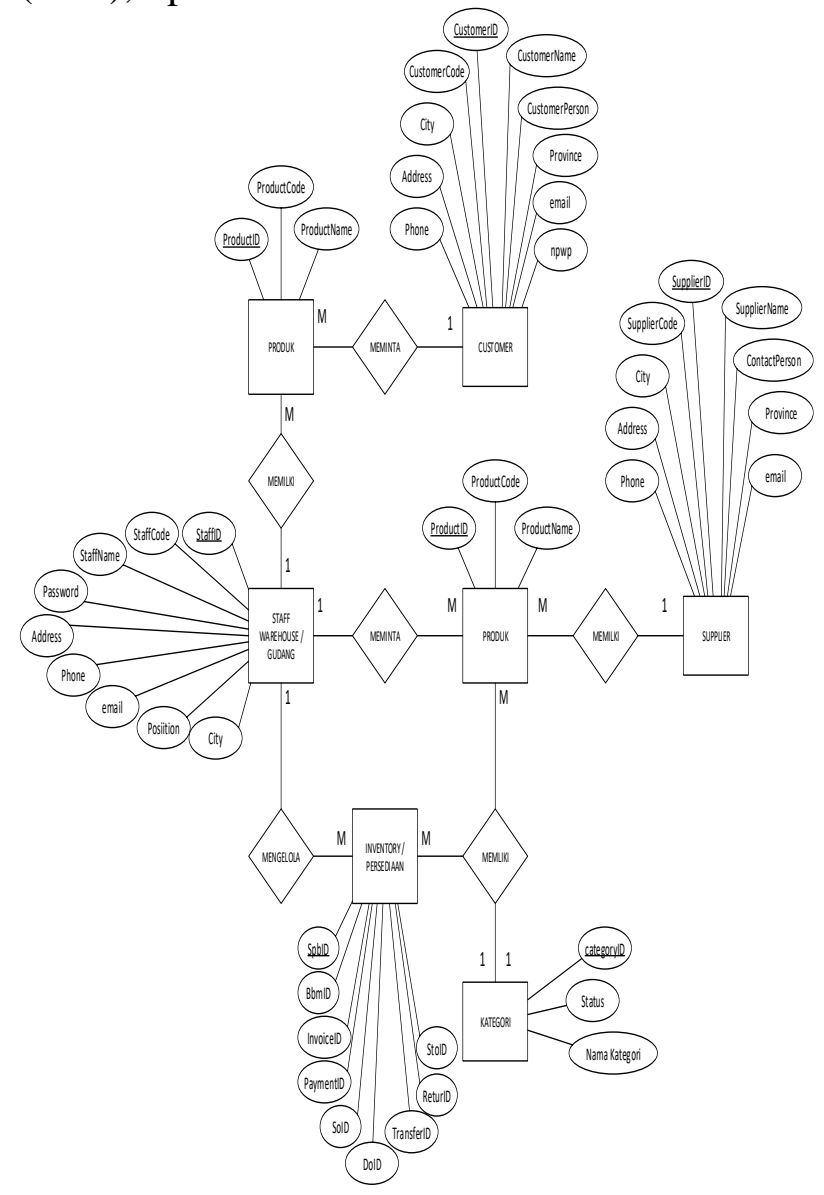

Gambar 2. Entity Relationship Diagram (ERD) 


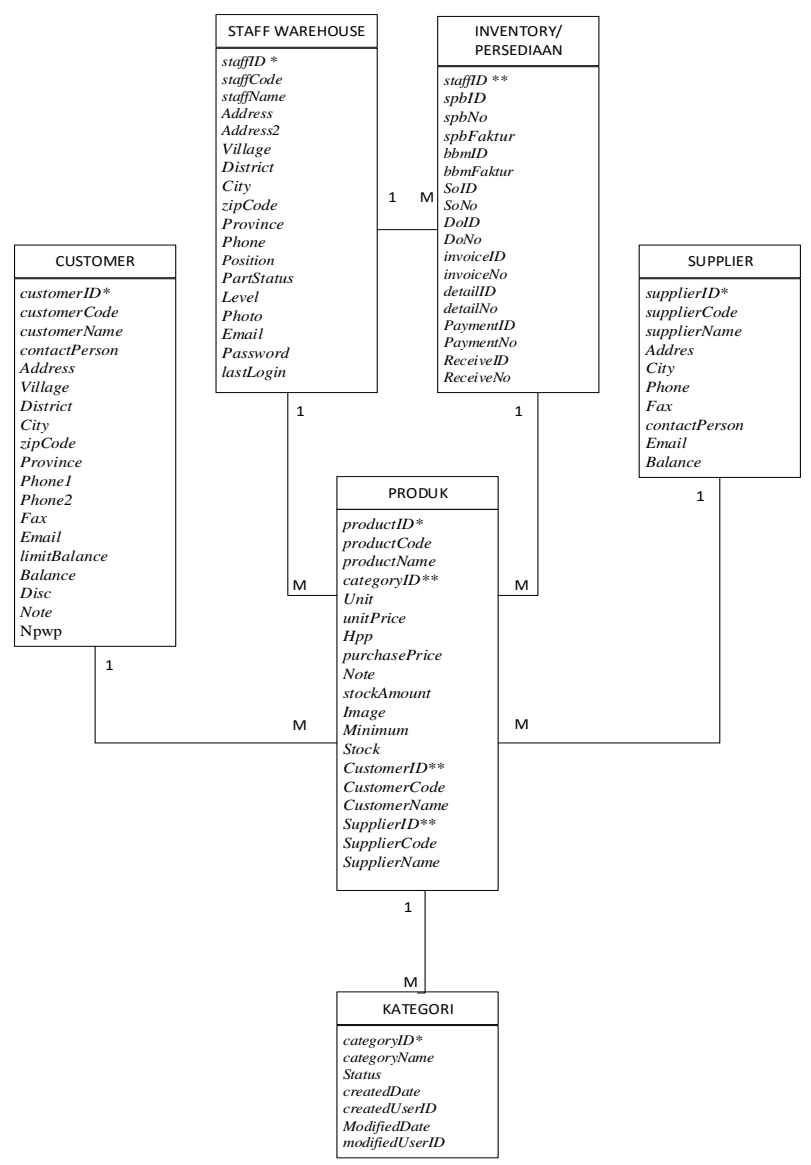

Gambar 3. Logical Record Structure (LRS)

\section{Rancangan Struktur Navigasi}

Struktur navigasi website digunakan untuk menggambarkan secara garis besar bagaimana isi dan susunan dari sebuah website secara menyeluruh. Pembuatan navigasi website ini akan membantu nantinya ketika akan membuat rancangan seluruh halaman web.

Adapun susunan struktur navigasi pada sistem Inventory PT. Sanghiang Perkasa berbasis web diantaranya:

Struktur navigasi admin digunakan untuk menggambarkan isi dari halaman admin. Dalam rancangan navigasi ini penulis menggunakan struktur navigasi campuran (composite). Sehingga akan mempermudah membuat halaman admin. Berikut adalah struktur navigasi halaman admin:

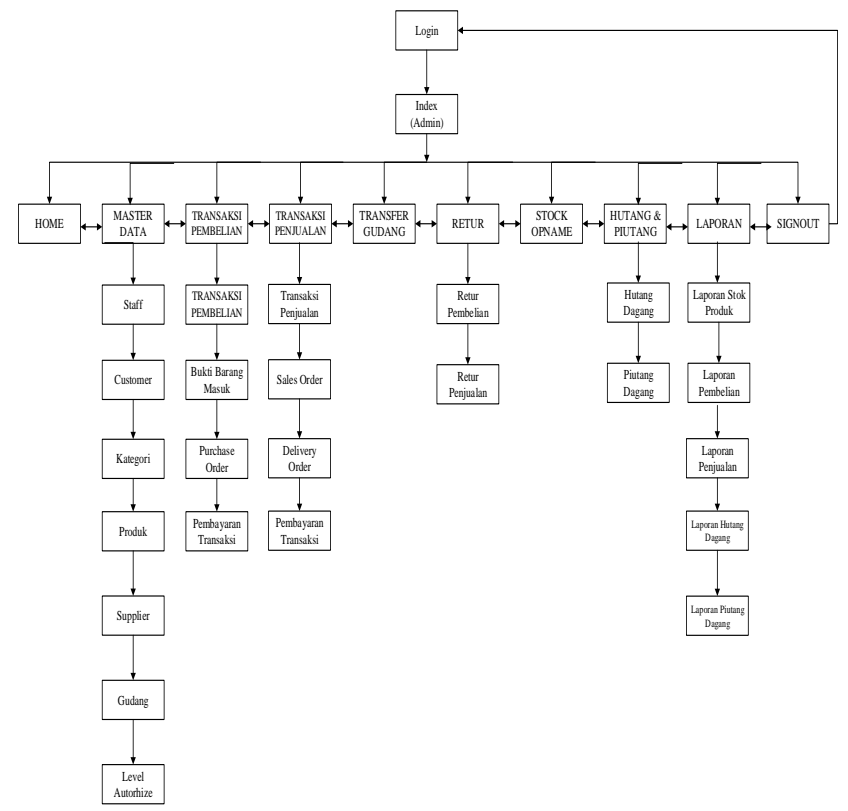

Gambar 4. Struktur Navigasi Admin

Struktur navigasi user bertujuan untuk menggambarkan isi dari halaman user. Dalam rancangan ini penulis menggunakan struktur navigasi campuran (composite). Berikut adalah struktur navigasi halaman user: 


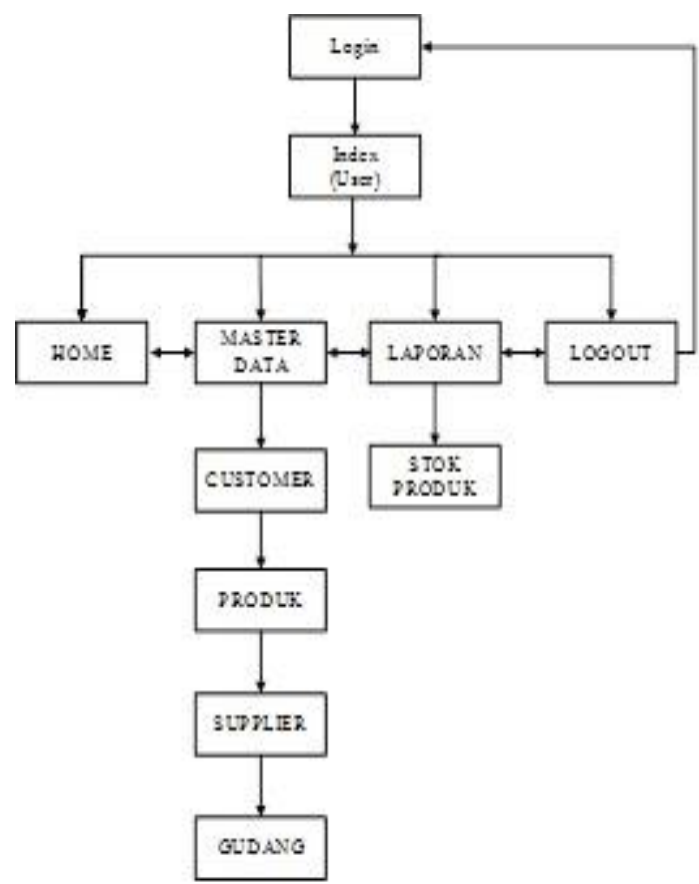

Gambar 5. Struktur Navigasi User

Struktur navigasi Spv bertujuan untuk memberikan hasil laporan dan pengontrolan terhadap bawahan. Dalam rancangan ini penulis menggunakan struktur navigasi campuran (composite). Berikut adalah struktur navigasi halaman Spv:

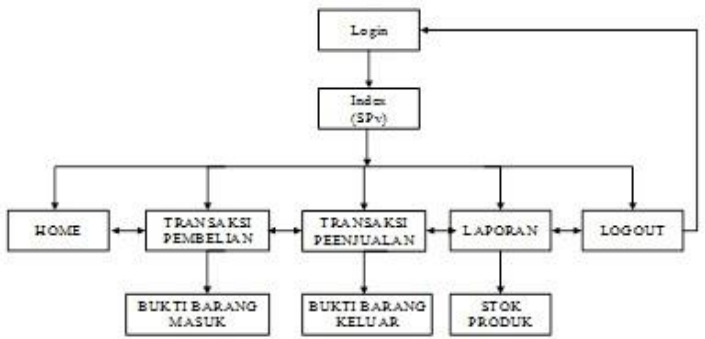

Gambar 6. Struktur Navigasi Spv

Struktur navigasi TOP bertujuan untuk memberikan seluruh hasil laporan dan pengontrolan terhadap bawahan. Dalam rancangan ini penulis menggunakan struktur navigasi campuran (composite). Berikut adalah struktur navigasi halaman Spv:

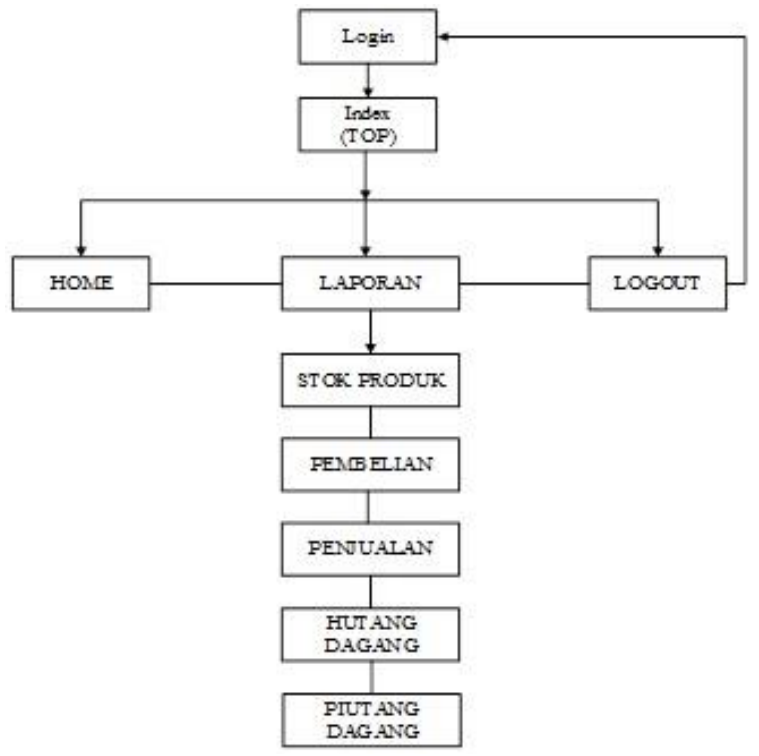

Gambar 7. Struktur Navigasi Top

\section{Implementasi}

Implementasi Rancangan Antar Muka. Rancangan Antar Muka pada Website Persediaan Barang ini terdiri dari:

Form Halaman Login

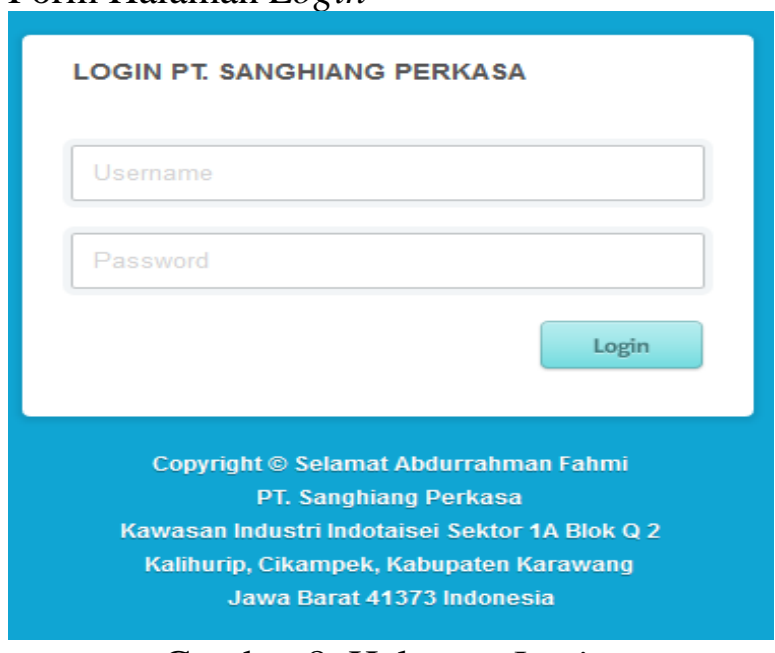

Gambar 8. Halaman Login

Halaman login merupakan tampilan awal untuk hak akses user, admin dan SPVdengan menginputkan username kemudian password 
Form Halaman Utama Admin

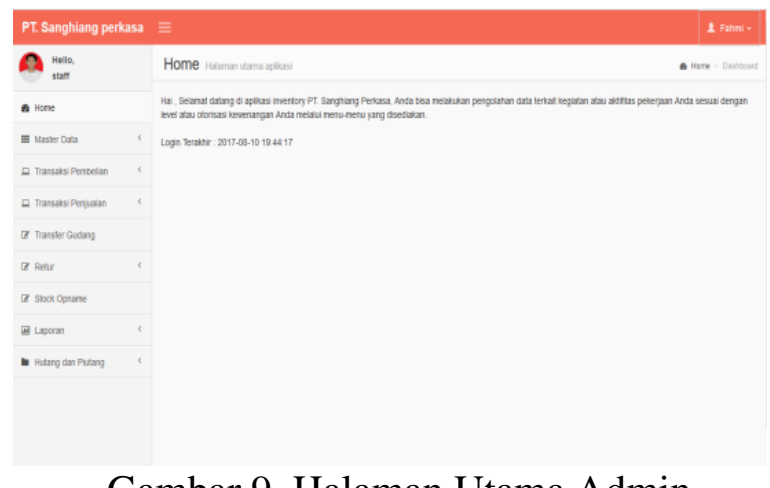

Gambar 9. Halaman Utama Admin

Didalam halaman utama admin terdapat menu master data, transaksi pembelian, transaksi penjualan, transfer gudang, retur, stock opname, laporan dan pencatatan hutang piutang.

Form Halaman Manajemen Customer

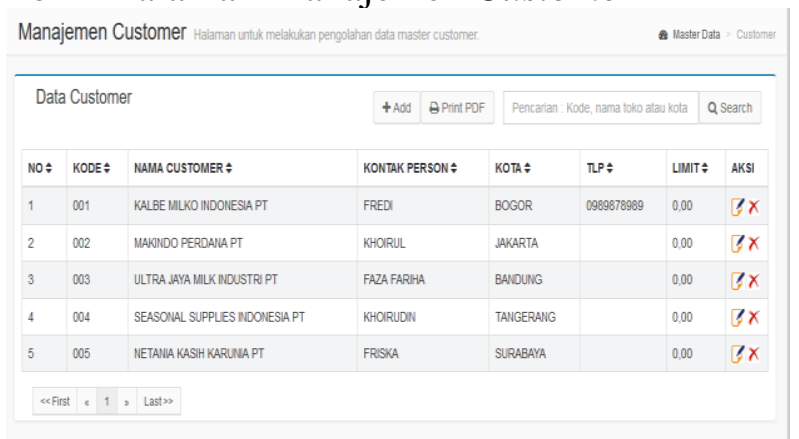

Gambar 10. Halaman Manajemen Customer

Didalam halaman manajemen customer terdapat informasi mengenai nama-nama customer, dapat ditambah atau dihapus kemudian dari data tersebut dapat diprint dengan tipe file PDF.

Form Halaman Manajemen Supplier

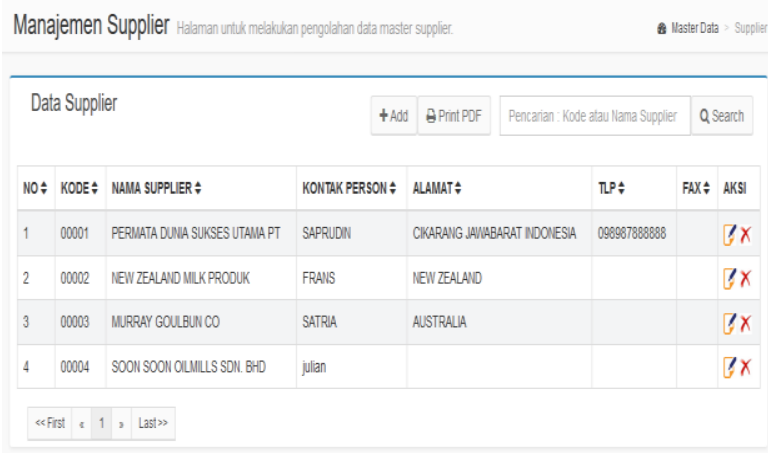

\section{Gambar 11. Halaman Manajemen Supplier}

Didalam halaman manajemen customer terdapat informasi mengenai nama-nama supplier, dapat ditambah atau dihapus kemudian dari data tersebut dapat diprint dengan format file PDF.

Form Halaman Pembayaran Transaksi Pembelian

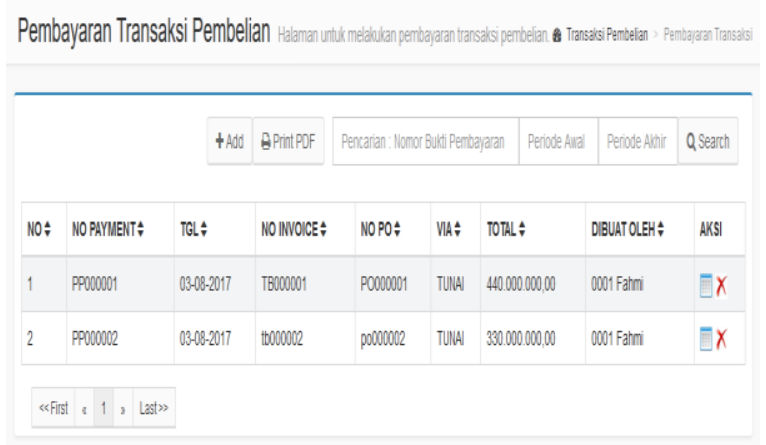

Gambar 12. Halaman Pembayaran Transaksi Pembelian

Pada halaman pembayaran transaksi pembelian terdapat informasi mengenai no invoice, tgl. Total pembelian, info user yang melakukan transaksi hingga semua informasi tersebut dapat diprint dengan format PDF. 


\section{Form Halaman Laporan Stock Produk}

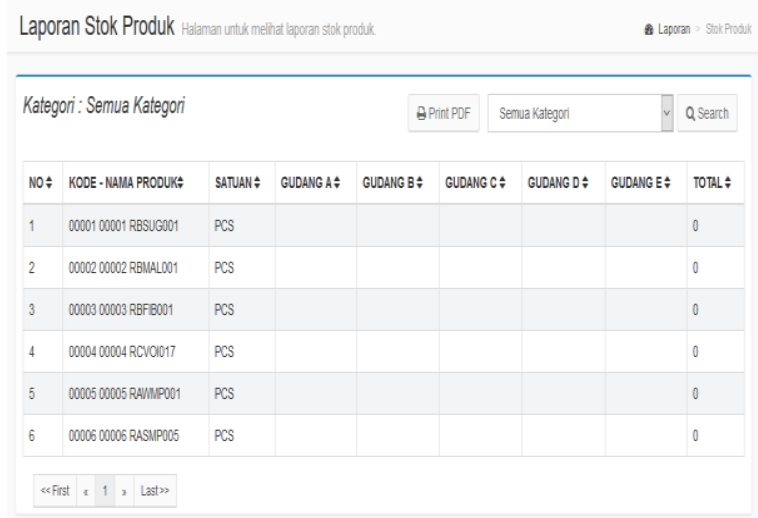

\section{Gambar 13. Halaman Laporan Stock Produk}

Pada halaman laporan stock produk terdapat informasi mengenai kode nama produk, satuan dan posisi gudang yang menyimpan produk atau barang tersebut, semua informasi tersebut dapat diprint dengan format PDF.

\section{Pengujian}

Tabel 2 Pengujian Pembayaran Transaksi

\section{Pembelian}

\begin{tabular}{|c|c|c|c|c|c|}
\hline NO. & $\begin{array}{l}\text { Sekeario } \\
\text { Pengujian }\end{array}$ & Test Case & $\begin{array}{l}\text { Hasil yang } \\
\text { diharapkan }\end{array}$ & $\begin{array}{c}\text { Hasil } \\
\text { Pengujian }\end{array}$ & Kesimpulan \\
\hline 1. & $\begin{array}{l}\text { Semua } \\
\text { tidak kolom } \\
\text { Kemudian } \\
\text { kliksimpan. } \\
\text { kliksing }\end{array}$ & $\begin{array}{l}\text { No. } \\
\text { Faktur:(Tidak } \\
\text { diisi) } \\
\text { Pembayaran: } \\
\text { (tidak diisi) }\end{array}$ & $\begin{array}{l}\text { Sistem akan } \\
\text { menampilkan } \\
\text { "please fill } \\
\text { out this } \\
\text { field". }\end{array}$ & $\begin{array}{l}\text { Sesuai } \\
\text { Harapan }\end{array}$ & Valid \\
\hline 2. & $\begin{array}{l}\text { Kolom } \\
\text { Pembayaran } \\
\text { tidak diisi. } \\
\text { Kemudian } \\
\text { Tekan enter. }\end{array}$ & $\begin{array}{l}\text { No. Faktur: } \\
\text { (TB00001) } \\
\text { Pembayaran: } \\
\text { (tidak diisi) }\end{array}$ & $\begin{array}{l}\text { Sistem akan } \\
\text { menampilkan } \\
\text { "please fill } \\
\text { out this } \\
\text { field". }\end{array}$ & $\begin{array}{l}\text { Sesuai } \\
\text { Harapan }\end{array}$ & Valid \\
\hline 3. & $\begin{array}{lr}\text { Kolom } & \text { No } \\
\text { Faktur riisi } \\
\text { dengan } & \text { Format } \\
\text { salah } & \text { Kemudian } \\
\text { Tekan enter. }\end{array}$ & $\begin{array}{l}\text { No. Faktur: } \\
\text { (TG00001) } \\
\text { Pembayaran: } \\
\text { (Tunai) }\end{array}$ & $\begin{array}{l}\text { Sistem akan } \\
\text { menampilkan } \\
\text { "No Eaktur } \\
\text { ini tidak di } \\
\text { gunakan". }\end{array}$ & $\begin{array}{l}\text { Sesuai } \\
\text { Harapan }\end{array}$ & Valid \\
\hline 4. & $\begin{array}{lr}\text { Kolom ro No } \\
\text { Faktur diisi } \\
\text { dengan Format } \\
\text { yang sudah } \\
\text { double di pakai } \\
\text { Kemudian } \\
\text { Tekan enter. } \\
\end{array}$ & $\begin{array}{l}\text { No. Faktur: } \\
\text { (TB00001) } \\
\text { Pembayaran: } \\
\text { (Tunai) }\end{array}$ & $\begin{array}{l}\text { Sistem akan } \\
\text { menampilkan } \\
\text { "Nomor } \\
\text { Faktur ini } \\
\text { telah Lunas } \\
\text { dibayarkan". }\end{array}$ & $\begin{array}{l}\text { Sesuai } \\
\text { Harapan }\end{array}$ & Valid \\
\hline 5. & $\begin{array}{lr}\text { Kolom } & \text { No } \\
\text { Faktur diisi } \\
\text { dengan Format } \\
\text { yang benar } \\
\text { Kemudian } \\
\text { Tekan enter. }\end{array}$ & $\begin{array}{l}\text { No. Faktur: } \\
\text { (TB00002) } \\
\text { Pembayaran: } \\
\text { (Tunai) }\end{array}$ & $\begin{array}{l}\text { Sistem akan } \\
\text { menampilkan } \\
\text { "Data } \\
\text { Pembayaran } \\
\text { Transaksi. } \\
\text { akan } \\
\text { bertambah". }\end{array}$ & $\begin{array}{l}\text { Sesuai } \\
\text { Harapan }\end{array}$ & Valid \\
\hline
\end{tabular}

Tabel 3. Pengujian Stock Opname

\begin{tabular}{|c|c|c|c|c|c|}
\hline NO. & $\begin{array}{l}\text { Sekeario } \\
\text { Pengujian }\end{array}$ & Test Case & $\begin{array}{l}\text { Hasil yang } \\
\text { diharapkan }\end{array}$ & $\begin{array}{c}\text { Hasil } \\
\text { Pengujian }\end{array}$ & Kesimpulan \\
\hline 1. & $\begin{array}{l}\text { Semua } \\
\text { kolom tidak } \\
\text { diisi. } \\
\text { Kemudian } \\
\text { klik Simpan. }\end{array}$ & $\begin{array}{l}\text { Gudang: } \\
\text { (Tidak di isi) } \\
\text { Kode Produk: } \\
\text { (Tidak di isi) } \\
\text { Stock Nyata: } \\
\text { (Tidak di isi) }\end{array}$ & $\begin{array}{l}\text { Sistem akan } \\
\text { menampilkan } \\
\text { "please fill } \\
\text { out this } \\
\text { field". }\end{array}$ & $\begin{array}{l}\text { Sesuai } \\
\text { Harapan }\end{array}$ & Valid \\
\hline 2. & $\begin{array}{l}\text { Kolom Kode } \\
\text { Produk, } \\
\text { Stock Nyata } \\
\text { tidak di isi. } \\
\text { kemudian } \\
\text { klik Simpan }\end{array}$ & $\begin{array}{l}\text { Gudang: } \\
\text { (00001 } \\
\text { gudang A) } \\
\text { Kode Produk: } \\
\text { (Tidak di isi) } \\
\text { Stock Nyata: } \\
\text { (Tidak di isi) }\end{array}$ & $\begin{array}{l}\text { Sistem akan } \\
\text { menampilkan } \\
\text { "please fill } \\
\text { out } \text { this } \\
\text { field". }\end{array}$ & $\begin{array}{l}\text { Sesuai } \\
\text { Harapan }\end{array}$ & Valid \\
\hline 3. & $\begin{array}{l}\text { Kolom Stock } \\
\text { Nyata tidak } \\
\text { di isi. } \\
\text { kemudian } \\
\text { klik Simpan }\end{array}$ & $\begin{array}{l}\text { Gudang: } \\
\text { (00001 } \\
\text { gudang A) } \\
\text { Kode Produk: } \\
\text { (000001) } \\
\text { Stock Nyata: } \\
\text { (Tidak di isi) }\end{array}$ & $\begin{array}{l}\text { Sistem akan } \\
\text { menampilkan } \\
\text { "please enter } \\
\text { a number". }\end{array}$ & $\begin{array}{l}\text { Sesuai } \\
\text { Harapan }\end{array}$ & Valid \\
\hline 4. & $\begin{array}{l}\text { Semua } \\
\text { kolom } \\
\text { dengan } \\
\text { benar di isi, } \\
\text { kemudian } \\
\text { klik Simpan }\end{array}$ & $\begin{array}{l}\text { Gudang: } \\
\text { (00001 } \\
\text { gudang A) } \\
\text { Kode Produk: } \\
\text { (000001)Stock } \\
\text { Nyata: (50) }\end{array}$ & $\begin{array}{l}\text { Sistem akan } \\
\text { menampilkan } \\
\text { "Detail Stock } \\
\text { Opname". }\end{array}$ & $\begin{array}{l}\text { Sesuai } \\
\text { Harapan }\end{array}$ & Valid \\
\hline
\end{tabular}

Tabel 4. Pengujian Sales Order

\begin{tabular}{|c|c|c|c|c|c|}
\hline NO. & $\begin{array}{l}\text { Sekearie } \\
\text { Pengujian }\end{array}$ & Test Case & $\begin{array}{c}\text { Hasil yang } \\
\text { diharapkan }\end{array}$ & $\begin{array}{c}\text { Hasil } \\
\text { Pengujian }\end{array}$ & Kesimpulan \\
\hline 1. & $\begin{array}{l}\text { Semua kolom } \\
\text { tidak diisi. } \\
\text { Kemudian klik } \\
\text { Add }\end{array}$ & $\begin{array}{l}\text { Kolom } \\
\text { Customer: } \\
\text { (kosong) }\end{array}$ & $\begin{array}{l}\text { Sistem akan } \\
\text { menampilkan } \\
\text { "kolom } \\
\text { tambah } \\
\text { item". }\end{array}$ & $\begin{array}{l}\text { Sesuai } \\
\text { Harapan }\end{array}$ & Valid \\
\hline 2. & $\begin{array}{l}\text { Kolom kode } \\
\text { produk. } \\
\text { masukan harga, } \\
\text { Qty tidak di isi } \\
\text { kemudian klik } \\
\text { simpan. }\end{array}$ & $\begin{array}{l}\text { Kode produk: } \\
\text { (tidak diisi) } \\
\text { Masukan } \\
\text { harga: (tidak } \\
\text { diisi) } \\
\text { Qty: (tidak } \\
\text { diisi) }\end{array}$ & $\begin{array}{l}\text { Sistem akan } \\
\text { menampilkan } \\
\text { "please fill } \\
\text { out this } \\
\text { field". }\end{array}$ & \begin{tabular}{|l|} 
Sesuai \\
Haxapan
\end{tabular} & Valid \\
\hline 3. & $\begin{array}{l}\text { Kolom } \\
\text { masukan harga, } \\
\text { Qty tidak di isi } \\
\text { kemudian klik } \\
\text { simpan. }\end{array}$ & $\begin{array}{l}\text { Kode produk: } \\
(00001) \\
\text { Masukan } \\
\text { harga: (tidak } \\
\text { diisi) } \\
\text { Qty: (tidak } \\
\text { disi) }\end{array}$ & $\begin{array}{l}\text { Sistem akan } \\
\text { menampilkan } \\
\text { "please fill } \\
\text { out this } \\
\text { field". }\end{array}$ & \begin{tabular}{|l|} 
Sesuai \\
Haxapan
\end{tabular} & Valid \\
\hline 4. & $\begin{array}{l}\text { Kolom Oty } \\
\text { tidak di isi } \\
\text { kemudian klik } \\
\text { simpan. }\end{array}$ & $\begin{array}{l}\text { Kode produk: } \\
(00001) \\
\text { Masukan } \\
\text { harga: }(50000) \\
\text { Qty: (tidak } \\
\text { diisi) }\end{array}$ & $\begin{array}{l}\text { Sistem akan } \\
\text { menampilkan } \\
\text { "please enter } \\
\text { a number". }\end{array}$ & \begin{tabular}{|l|} 
Sesuai \\
Haxapan
\end{tabular} & Valid \\
\hline 5. & $\begin{array}{l}\text { Kolom di isi } \\
\text { dengan benar } \\
\text { kemudian klik } \\
\text { simpan. }\end{array}$ & $\begin{array}{l}\text { Kode produk: } \\
\text { (00001) } \\
\text { Masukan } \\
\text { harga: }(50000) \\
\text { Qty: }(50)\end{array}$ & \begin{tabular}{|l|} 
Sistem akan \\
menampilkan \\
"Data Sales \\
Order akan \\
bertambah".
\end{tabular} & \begin{tabular}{|l|} 
Sesuai \\
Haxapan
\end{tabular} & Valid \\
\hline
\end{tabular}

Jurnal Interkom: Jurnal Publikasi Ilmiah Bidang Teknologi Informasi dan Komunikasi

Volume 15 Nomor 04 Bulan Januari - Tahun 2021 
Tabel 5. Pengujian Delivery Order

\begin{tabular}{|c|c|c|c|c|c|}
\hline NO. & $\begin{array}{l}\text { Sekearie } \\
\text { Pengujian }\end{array}$ & Test Case & $\begin{array}{l}\text { Hasil yang } \\
\text { diharapkan }\end{array}$ & $\begin{array}{c}\text { Hasil } \\
\text { Pengujian }\end{array}$ & Kesimpulan \\
\hline 1. & $\begin{array}{l}\text { Semua } \\
\text { kolom tidak } \\
\text { diisi. } \\
\text { Kemudian } \\
\text { klik Simpan. }\end{array}$ & $\begin{array}{l}\text { Kinim: (tidak } \\
\text { diisi) } \\
\text { Jumnlah } \\
\text { kinim: (tidak } \\
\text { di isi) } \\
\text { Dari Gudang } \\
\vdots \quad \text { (tidak di } \\
\text { isi) } \\
\end{array}$ & $\begin{array}{l}\text { Sistem akan } \\
\text { menampilkan } \\
\text { "please fill } \\
\text { out } \text { this } \\
\text { field". }\end{array}$ & $\begin{array}{l}\text { Sesuai } \\
\text { Harapan }\end{array}$ & Valid \\
\hline 2. & $\begin{array}{l}\text { Kolom } \\
\text { Jumlah } \\
\text { kirim dan } \\
\text { dari gudang } \\
\text { tidak di isi } \\
\text { kemudian } \\
\text { klik Simpan. }\end{array}$ & $\begin{array}{l}\text { Kinim: (YA) } \\
\text { Jumlah } \\
\text { kirim: (tidak } \\
\text { di isi) } \\
\text { Dari Gudang } \\
\vdots \text { (tidak di } \\
\text { isi) }\end{array}$ & $\begin{array}{l}\text { Sistem akan } \\
\text { menampilkan } \\
\text { "please enter } \\
\text { a number". }\end{array}$ & $\begin{array}{l}\text { Sesuai } \\
\text { Harapan }\end{array}$ & Valid \\
\hline 3. & $\begin{array}{l}\text { Kolom dan } \\
\text { gudangtidak } \\
\text { di isi } \\
\text { kemudian } \\
\text { klik Simpan }\end{array}$ & $\begin{array}{l}\text { Kinim: (YA) } \\
\text { Jumlah } \\
\text { kirim: (50) } \\
\text { Dari Gudang } \\
\vdots \quad \text { (tidak di } \\
\text { isi) }\end{array}$ & $\begin{array}{l}\text { Sistem akan } \\
\text { menampilkan } \\
\text { "Please } \\
\text { Select an } \\
\text { Item in the } \\
\text { List". }\end{array}$ & $\begin{array}{l}\text { Sesuai } \\
\text { Harapan }\end{array}$ & Valid \\
\hline 4. & $\begin{array}{l}\text { Kolom di isi } \\
\text { semua } \\
\text { dengan benar }\end{array}$ & $\begin{array}{l}\text { Kirim: (YA) } \\
\text { Jumlah } \\
\text { kirim: (50) } \\
\text { Dari Gudang } \\
\text { : (Gudang A) }\end{array}$ & $\begin{array}{l}\text { Sistem akan } \\
\text { menampilkan } \\
\text { "Data } \\
\text { Delivery } \\
\text { Order akan } \\
\text { bertambah". }\end{array}$ & $\begin{array}{l}\text { Sesuai } \\
\text { Harapan }\end{array}$ & Valid \\
\hline
\end{tabular}

\section{Penutup}

\section{a. Simpulan}

Setelah melakukan analisa dan perancangan serta implementasi yang telah di tuangkan kedalam bab - bab sebelumnya, maka dalam bab ini penyusun akan memberikan kesimpulan dan saran yang di harapkan membantu kemajuan System Inventory ini. Adapun kesimpulannya sebagai berikut:

1. Dengan adanya System Inventory ini, perusahaan (bagian warehouse) dengan mudah mengetahui laporan persediaan barang / produk yang ada. Sehingga untuk membuat Planning jangka panjang-pun bisa lebih cepat dan akurat.

2. Mempercepat waktu untuk laporan kepada atasan (Top manajemen)

3. Mempermudah Sistem Penyimpanan Dokumen karena sudah terkomputerisasi dan bermuara kepada Database.

\section{Saran}

1. Lebih baik menggunakan server mandiri, sehingga dapat meminimalisir gangguan dari pihak lain karena jaringannya akan lebih private.

2. Untuk mengantisipasi hal-hal yang tidak diharapkan, maka sebaiknya dilakukan backup database secara berkala.

3. Untuk penelitian berikutnya diharapkan adanya laporan yang berhubungan dengan bidang akuntansi.

\section{DAFTAR PUSTAKA}

[1] G. A. Syafarina, "Perancangan Aplikasi Inventory Barang Materials Dan Product," Technol. J. Ilm., vol. 7, no. 1, pp. 25-33, 2016.

[2] I. K. Sriwana, M. L. Christia, E. Ellytasia, and G. Chandiawan, "Perancangan Sistem Informasi Inventory Pt. Abc," J. Ilm. Tek. Ind., vol. 6, no. 1, pp. 9-19, 2019, doi: 10.24912/jitiuntar.v6i1.3019.

[3] M. R. Borroek, "Perancangan Sistem Informasi Pembayaran Pajak Aset Tetap Pada Stikom Dinamika Bangsa Jambi," J. Ilm. Media Sisfo, vol. 8, no. 3, pp. 150-158, 2017, [Online]. Available: http://ejournal.stikomdb.ac.id/index.php/mediasisfo/article/ view/155.

[4] R. Pratomo, P. S. Informatika, K. Gedong, P. Rebo, and J. Timur, "Perancangan Sistem Aplikasi Inventory Dan Penjualan Di," vol. 01, no. 01, pp. 95-102, 2020.

[5] J. Simarmata, Rekayasa Peraangkat Lunak. YOGYAKARTA: ANDI YOGYAKARTA, 2010.

[6] Yuhefizar, Cara Mudah Membangun Website Interaktif Menggunakan CMS Joomla Edisi Revisi. Jakarta: Elex Media Komputindo, 2012.

[7] Fathansyah, Basis Data. Bandung: Informatika Bandung, 2015. 
[8] C. Tristianto, "Waterfalls," J. Teknol. Inf. ESIT, vol. XII, no. 01, pp. 8-22, 2018, doi: 10.5749/j.cttttv6b.5.

[9] D. D. Agus Heryanto, Hilmi Fuad, "Rancang Bangun Sistem Informasi Inventory Barang Berbasis Web Studi Kasus di PT. Infinetworks Global Jakarta," Sisfotek Glob., vol. 4, no. 2, pp. 2-5, 2014.

[10] A. Saputra, Mega Proyek 75 Juta Aplikasi Inventory berbasis Web. Cirebon: CV. Asfa Solution, 2016.

[11] A. Prasetyo and R. Susanti, "Sistem Informasi Penjualan Berbasis Web Pada PT. Cahaya Sejahtera Sentosa Blitar," J. Ilm. Teknol. Inf. Asia, vol. 10, no. 2, pp. 1-16, 2016.

[12] A. R. Sukamto and M. Shalahuddin, Rekayasa Perangkat Lunak (Terstruktur dan Berorientasi Objek). Bandung: Informatika, 2016. 